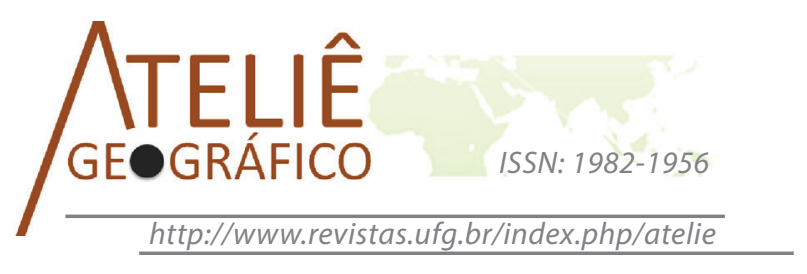

\title{
O pensamento geográfico e as aproximações com o humanismo: mundo e lugar nas letras das canções de Chico Buarque
}

\section{The geographic thought and approximations to humanism: world and place in lyrics of songs by Chico Buarque \\ La pensée géographique et les approximations avec l'humanisme: monde et lieu dans les paroles des chansons de Chico Buarque}

\author{
Carolina Machado Rocha Busch Pereira \\ Universidade Federal do Tocantins \\ carolinamachado@uft.edu.br
}

\begin{abstract}
Resumo
As letras das canções de Chico Buarque são portadoras de sentidos, revelam o mundo e possuem potência geográfica para dialogar com o mundo, o lugar e o cotidiano a partir das relações que emolduram a vida. Este ensaio tem o objetivo de refletir sobre a potência das letras das canções de Chico Buarque pela perspectiva geográfica humanista. O lugar tem um sentido e constitui parte essencial da existência humana. Consequentemente, a experiência no mundo-lugar está ligada à forma como se percebe o mundo a partir do espaço-tempo-sentido. Desta forma o ensaio apresenta as geografias reveladas pela letra das canções, a partir do tripé espaçotempo-sentido, que desvenda o lugar do sujeito, a existência e as possibilidades. As letras das canções de Chico Buarque dialogam com o lugar enquanto elo do mundo, expressão das relações, aproximações com o mundo a partir do espaçotempo-sentido. As geografias de mundo reveladas nas letras das canções de Chico Buarque apresentam as relações vividas em referências espaciais e temporais.
\end{abstract}

Palavras-chave: Geografia Cultural, Fenomenologia, Música.

\begin{abstract}
Chico Buarque's lyrics convey meanings and bring the world to light. They also have geographical strength to dialogue with the world, places and everyday life, starting from the relations that make up life. The aim of this essay is to reflect
\end{abstract}


on the strength of Chico Buarque's song lyrics from a humanistic geographical perspective. The place has a meaning and constitutes an essential part of human existence. Consequently, the experience in the place-world depends on the way by which the individual perceives the world from the space-time-sense. In this way the .the essay proposes the geographies shown in the song lyrics from the tripod spacetime-sense. Chico Buarque's song lyrics dialogue with the place as world link, expression of relationships, approaches to the world from the space-time-sense. The world geographies revealed in the lyrics of Chico Buarque songs show relationships lived in spatial and temporal references.

Key-words: Cultural Geography, Phenomenology, Music.

\begin{abstract}
Résumé
Les paroles des chansons Chico Buarque sont porteurs de significations, révéler le monde et ont le pouvoir géographique pour le dialogue avec le monde, le lieu et la vie quotidienne des relations que la vie de cadre. Cet essai vise à réfléchir sur la puissance des paroles de chansons de Chico Buarque point de vue géographique humaniste. L'endroit a un sens et une partie essentielle de l'existence humaine. Par conséquent, l'expérience dans le monde place est liée à la façon dont ils perçoivent le monde à partir de l'espace-temps-sens. De cette façon, le test montre géographiques révélés par la lettre des chansons du trépied espace-temps-sens, qui révèle la place du sujet, l'existence et les possibilités. Les paroles de chanson de Chico Buarque dialogue avec l'endroit comme lien de monde, l'expression de relations, les approches dans le monde de l'espace-temps-sens. Les géographies du monde révélés dans les paroles des chansons Chico Buarque montrent relations vivaient dans les références spatiales et temporelles.
\end{abstract}

Mots-clés: Géographie Culturelle, la Phénoménologie, Musique.

\title{
Considerações iniciais e aproximações fenomenológicas
}

Um dos importantes desenvolvimentos na Geografia Cultural, no último quarto do século XIX, foi a ascensão de um movimento denominado Geografia Humanista, que se aproxima fortemente da obra de Edmund Husserl, Martin Heidegger e de Maurice Merleau-Ponty, entre outros. Esse movimento enfatiza o conceito de lugar como uma noção central e determinante na investigação geográfica e tem como expoentes Yi-Fun Tuan, Edward Relph, Anne Buttimer e David Seamon, para citar alguns. De fato, a Geografia Humanista tem sido aliada a um modo de pensamento ambiental orientado para o estudo do lugar, e da Geografia concebida como uma ciência das essências que se referem à existência humana e à nossa experiência de mundo (HOLZER, 1997, p. 79).

A palavra 'lugar' significa originariamente ponta de lança. Na ponta de lança, tudo converge. No modo mais digno e extremo, o lugar é o que reúne e recolhe para si. O recolhimento percorre tudo e em tudo prevalece. Reunindo e recolhendo, o lugar desenvolve e preserva o que envolve não como uma cápsula isolada, mas atravessando com seu brilho e sua luz o que recolhe de maneira a somente assim entregá-lo à sua essência (HEIDEGGER, 2008, p. 27). 
O lugar, como uma entidade socialmente construída, é necessariamente investido de significado humano na perspectiva humanista, e, segundo Besse (2011, p. 133) "O lugar deve ser compreendido pelo geógrafo porque ele faz parte de suas possibilidades de existência, porque no fundo ele desvela uma possibilidade de ser no mundo, com o qual o geógrafo se comunica 'lateralmente'”,

O pressuposto para pensar a Geografia na atualidade é tomá-la como uma ciência que busca a compreensão das relações socioespaciais e que se volta para o lugar para compreender e interpretar o sentido das relações.

O saber geográfico dá forma a uma emoção, o que significa dizer que ele ordena a memória: para restituir a própria natureza desse choque, para guardar a intensidade, a linguagem deverá ir direto à presença da imagem, a seu poder de evocação e de fixação de uma direção do sentido (BESSE, 2011, p. 133).

Vivemos e nos relacionamos com um mundo cheio de significados. O debate sobre o lugar está imbricado na reflexão sobre o mundo, uma vez que construir o lugar é também construir a nós mesmos.

Compreender um lugar consiste em traduzir a emoção bruta que esse encontro faz nascer e crescer em nós, em outra linguagem possuidora de um poder de elucidação. Compreender é interpretar um sentido imediatamente percebido porque pertence ao próprio lugar (BESSE, 2011, p. 130).

Falar sobre o mundo é uma provocação geográfica das mais sérias, pois não há pergunta mais genuína e simples de ser feita do que: O que é mundo? Mas também é certo que não há investigação mais meritória do que a busca por compreender o mundo, ou mesmo refletir sobre este.

Todavia, uma advertência deve ser feita ao leitor: neste trabalho, o mundo é pensado a partir do prisma geográfico do presente. Este por sua vez contém o passado e o futuro. O presente é compreendido como o momento e o fragmento da história da humanidade ambientado no século XX, ou, na passagem da sociedade de produção para a sociedade de consumo como ensinou Kumar (1997) uma referência sociológica sobre as transformações da sociedade urbana ocidental.

Para Santos (2001), referência geográfica importante para a leitura do presente, o século XX é o grande marco da história recente e não somente pela mudança da sociedade de consumo, mas também pela importante transformação que ocorreu pós década de 1980 com as redes de computadores e a revolução cibernética e o advento das técnicas. Em reflexão sobre a totalidade como possibilidade de leitura do mundo, Santos (2009, p. 123), pondera que “o mundo se dá como latência, como um conjunto de possibilidades que ficam por aí, vagando, até que, chamadas a se realizar transformam-se em extenso, isto é, em qualidades e quantidades.".

A década de 1980 é identificada por Bauman (2002, 2008, 2009) e Harvey (2011), como o momento do início da consciência pós-moderna. Esses autores ressaltam a importância que as transformações sociais, políticas e econômicas trouxeram ao 
indivíduo e à sociedade. As transformações vividas pelo mundo e pela sociedade no século XX tiveram enormes consequências na vida e no mundo do presente.

Para Bauman (2002), as mudanças ocorridas neste mesmo período foram tão rápidas que não sabemos ao certo se vivemos um período de transição ou se realmente essas mudanças marcam um novo momento da História, que vai perdurar por séculos. O fato é que vivemos um presente em constante mudança, seja para uma nova forma de vida, seja para uma nova ordem social. A dificuldade de compreender o presente faz parte do momento em que vivemos.

Independentemente de a abordagem ser histórica, sociológica ou geográfica, cabe ressaltar que a ciência, em geral, busca compreender o mundo e as transformações da sociedade, e tem perseguido essa meta há muito tempo. Na Grécia antiga, por exemplo, Aristóteles concebia o mundo a partir da ideia de totalidade. Isso equivalia a definir o mundo como a ordem imutável do Universo. Da Grécia antiga até hoje, muitas mudanças ocorreram. Ideias e concepções foram alteradas e a reflexão sobre o mundo também recebeu ares novos. A ciência, em geral, permanece empenhada em pensar e refletir sobre o mundo principalmente com o intuito de desvendar o sentido e a razão da existência do mesmo. E por onde começaremos a construir o processo de aprendizagem sobre o mundo? Longe de ser tarefa fácil, compreender o mundo é um dos afazeres mais difíceis.

Com base no edifício teórico consistente da pesquisa e buscando harmonia entre as referências do trabalho, iniciaremos a reflexão sobre o mundo e sobre o lugar a partir dos preceitos da Fenomenologia, corrente filosófica que embasa a pesquisa.

\section{O mundo e o lugar na Geografia Humanista}

O mundo está para o lugar na mesma proporção e importância que o lugar está para o mundo, pois de acordo com Santos (2009, p. 315) "cada lugar é a sua maneira o mundo" o mesmo autor ainda complementa que "no lugar - um cotidiano compartido entre as mais diversas pessoas, firmas e instituições - cooperação e conflito são a base da vida em comum" (SANTOS, 2009, p. 322).

O mundo, para Heidegger (2005), é entendido como o campo constituído pelas relações do homem com as coisas e com os outros homens. O conceito ser-no-mundo, desenvolvido por Heidegger (2005), designa o modo de ser do homem "situado no meio do ente e relacionando-se com ele" (ABBAGNANO, 2003, p. 779).

O mundo pleno de significação é chamado, na tradição fenomenológica inspirada em Husserl, de Lebenswelt, ou seja, de mundo da vida. O termo Lebenswelt introduzido por Husserl em sua obra Krisis foi utilizado para designar "o mundo em que vivemos intuitivamente, com suas realidades, do modo como se dão primeiramente na experiência simples e depois também nos modos em que sua validade se torna oscilante" (ABBAGNANO, 2003, p. 801). Desta forma, o mundo da vida não é apenas uma visão de mundo, é, um mundo no qual habitamos e que chamamos de realidade.

Pensar sobre o mundo não foi tarefa atribuída aos filósofos, exclusivamente; cientistas, como Einstein, também formularam conceituações sobre este. Para Einstein, 
o mundo "é mistério da vida, é forte emoção [...] é sentimento que suscita a beleza e a verdade, cria a arte e a ciência. Se alguém não conhece esta sensação ou não pode experimentar espanto ou surpresa, já é um morto-vivo e seus olhos se cegaram" (EINSTEIN, 1981, p. 12).

No entanto, certamente, coube aos filósofos fazer as reflexões com mais fôlego. Heidegger foi um dos pensadores que se dedicou a pensar sobre o mundo. No início do terceiro capítulo de Ser e Tempo, Heidegger (2005) mostrou que o conceito de 'mundo' não era tomado como um atributo da existência (mundanalidade), mas como objeto. A razão atribuída a esta desarticulação homem-mundo é precisamente a imagem ontológica que se tem do mundo e faz com que o mundo se torne um instrumento. Como resultado, a compreensão do mundo padece de reflexão. Desta forma, o mundo, para Heidegger, "significa o conjunto de relações entre o homem e os outros seres: a totalidade de um campo de relações" (ABBAGNANO, 2007, p. 801).

Para os existencialistas, em termos filosóficos todo objeto tem uma existência, um sentido e uma essência. E essa essência é o próprio sentido (SARTRE, 2002).

A verdadeira tarefa da filosofia, segundo Husserl (1990), não é tanto alcançar um conhecimento abstrato dos objetos, mas estabelecer uma relação de trabalho com o nosso mundo. A experiência direta do mundo, afirma Heidegger (2008), em sintonia com o conceito aristotélico de práxis é a fonte direta do conhecimento. Já Abbagnano (2003) entende por mundo a totalidade das coisas existentes, qualquer que seja o significado de existência.

Merleau-Ponty (1999) dizia que a tarefa da filosofia deveria ser o diálogo com "o mundo de toda a gente", expressão merleau-pontyana que se refere à necessidade de a filosofia dialogar com a cultura, com a experiência vivida, com a história, com a ciência e fundamentalmente com a arte. Para Merleau-Ponty, o mundo reflete a vida, a subjetividade e a cultura, porque o corpo é pleno de subjetividade e encontra-se recortado pela historicidade, sendo que essa condição corpórea se desdobra em decisões teóricas e práticas da vida e do conhecimento. Para Merleau-Ponty, o corpo é feito da mesma matéria do mundo: "A cada instante também eu fantasio acerca das coisas, imagino objetos ou pessoas cuja presença aqui não é incompatível com o contexto e todavia eles não se misturam ao mundo, eles estão adiante do mundo, no teatro do imaginário" (MERLEAU-PONTY, 1999, p. 9).

É a realidade do corpo que nos permite sentir e, portanto, perceber o mundo, os objetos, as pessoas. É a realidade do corpo que nos permite imaginar, sonhar, desejar, escolher e apreciar uma música. Para compreender o sentido da subjetividade, em Merleau-Ponty, precisamos compreender também a noção de liberdade, posto que o encontro do nosso ser interior, com o exterior, e, as escolhas que fazemos têm sempre lugar nas situações dadas e sobre as possibilidades abertas. Somos, ao mesmo tempo, um entrelaçamento do tempo natural, afetivo, histórico e geográfico. Os gostos pessoais, as preferências, as rejeições, os desejos, vão sendo configurados por meio dessa estrutura subjetiva com a qual correlacionamos o tempo, o corpo, o mundo, as coisas e os outros. O campo da subjetividade encontra-se recortado pela historicidade, pelos objetos da cultura, pelas relações sociais, tensões, contradições, paradoxos, afetos. Dessa maneira, 
a leitura de um livro e a apreciação de uma canção mobilizam sentidos que foram construídos nesse campo subjetivo.

Quanto ao conceito de mundo, os estudos de Merleau-Ponty (1999) contêm uma filosofia viva em movimento e seus textos se assemelham ao prazer da descoberta das coisas novas e belas do mundo: "O mundo não é aquilo que eu penso, mas aquilo que eu vivo; eu estou aberto ao mundo, comunico-me indubitavelmente com ele, mas não o possuo, ele é inesgotável” (MERLEAU-PONTY, 1999, p. 14).

A ideia de mundo assume neste trabalho o significado do conjunto de relações entre o homem e os outros seres, a totalidade de um campo de relações. O mundo não é uma alteridade, o mundo é vida e subjetividade; se não existíssemos, não haveria mundo. $\mathrm{O}$ mundo é criação humana. O mundo acontece no instante, na fração da vida e, por esta razão, é que o mundo e o lugar se encontram e que o mundo está no lugar. Quando terminar a vida humana, acabará o mundo. E se o mundo depende das relações entre os homens, podemos afirmar, sem medo de errar, que o mundo é troca, construção coletiva a partir da cultura, da arte, da linguagem, da política, da economia. Essa concepção de mundo está amparada nas bases da Fenomenologia.

A Fenomenologia significa antes de mais nada um conceito de método. Ela não caracteriza a consistência de fato do objeto da indagação filosófica, mas seu como [...] esse termo expressa um lema 'as coisas mesmas!'. Por oposição as construções soltas no ar e aos achados casuais; em oposição à admissão de conceitos apenas aparentemente verificados e aos falsos problemas verdadeiros. Portanto, o que a Fenomenologia mostra é aquilo que, acima de tudo e na maior parte dos casos, não se manifesta, o que está escondido, mas que é capaz de expressar o sentido e o fundamento daquilo que, acima de tudo e na maior parte dos casos, se manifesta. Nesse sentido a Fenomenologia é a única ontologia possível (ABBAGNANO, 2003, p. 512).

Normalmente, atribuímos existência aos espaços e às coisas, mas na realidade, sem nós, elas não existiriam. Pensar um espaço como existente, significa pensar em si próprio.

Marcel (1955, p. 45) afirmou que "quanto mais eu acentuar a objetividade das coisas, cortando o cordão umbilical que se liga à minha existência, mais converterei este mundo num espetáculo sentido como ilusório". Vivemos, atualmente, um mundo recheado de medos, inseguranças, angústias, incertezas, instabilidades e as características do mundo que também são do próprio ser, não permitem pensar em harmonia no mundo, em sustentabilidade do mundo (BAUMAN, 2008).

Ao pensar sobre o mundo, a investigação vai aos poucos procurando os caminhos da pesquisa de Eric Dardel (2011), que compreende a Geografia como ciência interessada em entender o homem no mundo circundante. A Geografia tem mostrado cada dia mais sua importância e sua contribuição para a delicada questão de desvendar o horizonte da vida humana no presente, no mundo, nas relações com o lugar e com o global, na contemporaneidade. 
Segundo Holzer (1997, p. 80), pensar sobre o mundo é essencial: "a palavra 'mundo' é fundamental para que se compreenda a relação entre a ciência geográfica essencial, ou fenomenológica, e a sua essência, que pode ser denominada geograficidade."

De acordo com Gratão e Marandola Jr. (2011, p. 70), a geograficidade compreendida "enquanto expressão da cultura e da identidade das pessoas com lugar", revela o mundo. E a letra da canção 'Paratodos' revela as geografias de mundo, enquanto expressão de cultura e de identidade.

Chico Buarque cidadão do mundo recupera em 'Paratodos' sua biografia e herança histórico-espacial.

\section{Paratodos}

Chico Buarque, 1993

O meu pai era paulista

Meu avô, pernambucano

O meu bisavô, mineiro

Meu tataravô, baiano

Meu maestro soberano

Foi Antonio Brasileiro

Foi Antonio Brasileiro

Quem soprou esta toada

Que cobri de redondilhas

Pra seguir minha jornada

E com a vista enevoada

Ver o inferno e maravilhas

Nessas tortuosas trilhas

A viola me redime

Creia, ilustre cavalheiro

Contra fel, moléstia, crime

Use Dorival Caymmi

Vá de Jackson do Pandeiro

Vi cidades, vi dinheiro

Bandoleiros, vi hospícios

Moças feito passarinho

Avoando de edifícios

Fume Ari, cheire Vinícius

Beba Nelson Cavaquinho

Para um coração mesquinho

Contra a solidão agreste

Luiz Gonzaga é tiro certo 


\author{
Pixinguinha é inconteste \\ Tome Noel, Cartola, Orestes \\ Caetano e João Gilberto \\ Viva Erasmo, Ben, Roberto \\ Gil e Hermeto, palmas para \\ Todos os instrumentistas \\ Salve Edu, Bituca, Nara \\ Gal, Bethania, Rita, Clara \\ Evoé, jovens à vista \\ O meu pai era paulista \\ Meu avô, pernambucano \\ O meu bisavô, mineiro \\ Meu tataravô, baiano \\ Vou na estrada há muitos anos \\ Sou um artista brasileiro
}

Segundo Scarlato (2003, p. 383), “quase sempre a Geografia trabalha os fenômenos populacionais de forma abstrata, na qual os números substituem os indivíduos e os comportamentos humanos são relegados a segundo plano". Todavia refletir sobre a questão populacional a partir da letra da canção 'Paratodos' revela geografias de mundo e expõe comportamentos humanos em primeiro plano. 'Paratodos' gravita em torno da migração, fenômeno populacional, que na letra da canção, dialoga com a construção da identidade brasileira e plural. Uma fração de mundo é revelada na canção.

'Paratodos' e para-o-mundo, visto que o mundo é de todos e as nossas origens, à semelhança do que está exposto na letra da canção, são as mais variadas.

Para a Geografia Humanista, a compreensão do sentido de espaço e lugar requer uma leitura fenomenológica e, por vezes, existencial. Para Tuan (1983, p. 151), o espaço transforma-se em lugar à medida que adquire definição e significado, ou seja, atinge a realidade mediante a experiência do sujeito o que implica, por sua vez,

[...] a capacidade de aprender a partir da própria vivência. Experienciar é aprender; significa atuar sobre o dado e criar a partir dele. O dado não pode ser conhecido em sua essência. O que pode ser conhecido é uma realidade que é um constructo da experiência, uma criação de sentimento e pensamento (TUAN, 1983, p. 10).

A concepção de Tuan foi influenciada pela fenomenologia de Heidegger e de Merleau-Ponty, reafirmando o interesse nas relações entre conhecimento e existência.

Construímos o lugar na mesma medida em que os lugares nos constroem. Esse debate é acolhido com certo conforto pela Geografia, quando realizado nas bases do humanismo. 
Para a fenomenologia, mundo e lugar são vistos como um par essencialmente inseparável, algo como o par espaço e lugar para a geografia. A dialética entre 'mundo' e 'lugar' é mais antiga e arraigada do que a do par 'espaço' e 'lugar'. $\mathrm{Na}$ geografia, esse par vem sendo discutido muito recentemente, e considero que envolve essências espaciais de natureza muito diversas: o 'lugar' está ligado a vivências individuais e coletivas a partir do contato do ser com seu entorno; enquanto o 'espaço' é uma racionalização abstrata, uma construção mental, que busca uniformizar e homogeneizar o ‘suporte físico’ (HOLZER, 2012, p. 290).

O lugar se apresenta no pensamento de Michel de Certeau (2003, 2012) como uma relação entre elementos que definem equilibrada e harmonicamente um determinado campo, ou um determinado espaço. O lugar não está separado da ação humana, porém é dependente dela e está nela imbricado. Ao discorrer sobre o cotidiano de Certeau (2012) pondera sobre o espaço a partir das estruturas narrativas, ou seja, enquanto as práticas espaciais são vistas como ações narrativas que se referem ao espaço, o lugar é visto como derivação do espaço. Segundo o autor, a partir do momento em que os relatos se referem ao espaço, eles também organizam os lugares e conferem alguma identidade a eles. Este autor utiliza a noção de estruturas narrativas como decodificadores do espaço e, portanto, como meios de ler o lugar: ler a cidade, ler o cotidiano, ler os afazeres e ler as práticas humanas realizadas no lugar (CERTEAU, 2003). Desta forma, o lugar não tem o mesmo significado para todos os seres. Um ser relaciona-se com o lugar de forma diferente de outro ser. O espaço em si é uma dimensão vazia sem contornos e definições precisas. Adota sentidos distintos e acepções diferenciadas não só nas diversas áreas do conhecimento, como também até mesmo dentro de uma mesma área como ocorre na Geografia, por exemplo. Neste sentido, Corrêa (1995, p. 15) explicita que "a palavra espaço tem o seu uso associado indiscriminadamente a diferentes escalas, global, continental, regional, da cidade, do bairro, da rua, da casa e de um cômodo no seu interior. " Acompanhando a reflexão de Corrêa (1995) a noção de espaço aos poucos vai adquirindo distintas formas. Na Geografia Humanista, o espaço adquire sentidos mais amplos e contornos ainda menos precisos e, talvez por esta razão, assuma um papel de destaque quando incorpora as categorias de lugar e paisagem e seu sentido geográfico.

A paisagem torna-se um conceito revalorizado, assim como a região, enquanto o conceito de território tem na Geografia Humanista uma de suas matrizes. O lugar passa a ser o conceito-chave mais relevante, enquanto o espaço adquire, para muitos autores, o significado de espaço vivido (CORRÊA, 1995, p. 15).

A Geografia, segundo Relph (1979, p. 16), necessita de uma abordagem fenomenológica, uma vez que os espaços são vividos e não somente percebidos, sentidos ou representados. Sendo assim, existem inúmeros espaços, porque existem várias experiências espaciais. A geograficidade está presente em todos os momentos da vida. Para Relph (1981), os lugares são intercambiáveis e sem fronteiras definidas, como as paisagens e os espaços que coincidem se alinham, se justapõem e se diferenciam num jogo permanentemente mutável.

Desta forma, para Relph $(1979 ; 1981)$ e Corrêa (1995), lugar é o conceito chave quando se fala de espaço vivido e, para a Geografia Humanista, os dois conceitos, em 
muitas ocasiões tornam-se sinônimos. O lugar assume valores e significados especiais para aqueles que nele vivem e é carregado de emotividade, fruto das relações pessoais.

Os pertences, parentes, amigos e a base territorial experienciada fazem parte do acervo íntimo do indivíduo. Pausa, movimento e morada conferem ao mundo vivido a distinção de lugar. As experiências nos locais de habitação, trabalho, divertimento, estudo e dos fluxos transformam os espaços em lugares, carregam em si experiência, logo, poesia, emoção, sensação de paz e segurança dos indivíduos que estão entre os "seus", tem uma conotação de pertinência por pertencer à pessoa e esta a ele, o que confere uma identidade mútua, particular aos indivíduos. Assim, o lugar é recortado emocionalmente nas experiências cotidianas. [...] Os geógrafos humanísticos insistem que o lugar é o lar, podendo ser a casa, a rua, o bairro, a cidade ou a nação. Enfim, qualquer ponto de referência e identidade (MELLO, 1990, p. 102).

O cotidiano é a categoria da existência que se presta a um tratamento geográfico do mundo vivido nas palavras de Santos (2009, p. 315). Se o espaço adquire sentido quando associado ao vivido e reflete o lugar e o mundo, a partir das relações, o mesmo acontece com o mundo e com o lugar. $\mathrm{O}$ espaço sem as relações, com o lugar ou com o mundo perde o sentido.

Para diferentes indivíduos, os espaços e os lugares podem não coincidir. $\mathrm{O}$ espaço, que para alguns adquiriu um status de lugar, para outros, poderá nada representar. De outra maneira, o que era há alguns segundos um espaço, poderá assumir a posição definitiva de lugar, na representação que um indivíduo faz desse espaço. E vice-versa. O que um dia foi um lugar carregado de boas impressões, poderá se tornar um espaço, ou um lugar topofóbico, por associação com eventos traumáticos ou desagradáveis ao indivíduo (TUAN, 1983, p. 155).

Em Heidegger, encontramos outra estrada para o caminhar teórico sobre o lugar.

Nessa tentativa de pensar, atentamente, tanto a relação entre lugar e espaço como também o relacionamento entre homem e espaço, a essência das coisas, que são lugares e que chamamos de coisas construídas, ganha luz. [...] O lugar acolhe, numa circunstância, a simplicidade de terra e céu, dos divinos e dos mortais, à medida que edifica em espaços a circunstância (HEIDEGGER, 2008, p. 137).

A ideia de circunstância - compreendida como estado ou condição de uma pessoa ou de uma coisa em determinado momento - associada à ideia de lugar reverbera no pensamento de Heidegger e caminha ao encontro da ideia de habitar e de pertencimento: "A referência do homem aos lugares e através dos lugares aos espaços repousa no habitar. A relação entre o homem e o espaço nada mais é do que um habitar pensado de maneira essencial " (HEIDEGGER, 2008, p. 27). Marandola Jr. (2012, p. 228), em trabalho sobre o 'Lugar enquanto circunstancialidade', inicia a reflexão, resgatando a importância que o lugar tem no cotidiano e como é a partir dele que nos inserimos no mundo:

É pelo lugar que nos identificamos, ou nos lembramos, constituindo assim a base de nossa experiência no mundo. A circunstancialidade [...] advém da 
possibilidade de abertura para compreender enquanto eventualidade relativa uma posição e uma situação que enfatiza o sentido relacional do ser-e-estar-nomundo, ao mesmo tempo que dá o devido peso à realidade fenomênica do ser-aí e sua espacialidade. (MARANDOLA JR., 2012, p. 230).

A circunstancialidade é pensada a partir da ideia de mundo circundante de Heidegger (2005) e "lugar, enquanto circunstancialidade, é a busca por um entendimento fenomenológico da experiência contemporânea, a qual não pode se furtar da resistência do espaço às nossas intencionalidades e volições" (MARANDOLA JR., 2012, p. 230).

$\mathrm{O}$ que se mostra fundamental na esteira do pensamento sobre o lugar, em Heidegger, é a importância atribuída à relação entre ser-e-estar em seu lugar, relação esta de um autêntico e essencial pertencimento ao lugar. O conceito de lugar, em Heidegger, aponta para uma permanência que comporta em si a mobilidade (PÁDUA, 2005).

Pádua $(2005$, p. 40), em sua tese sobre Heidegger, alerta que somente a espacialidade mundana pode derivar lugar ou qualquer tipo particular de espaço. O conceito de 'espaço' em Heidegger, assume o sentido de derivado, isto é, sua compreensão se dá a partir da compreensão da espacialidade fática ${ }^{3}$, que se origina e se revela no mundo. Mundo e lugar estão juntos e, são inseparáveis, tanto no pensamento de Heidegger (2008) como também no de Santos (2008).

\section{O tempo e o lugar em Chico Buarque}

Saramago (2012) reflete sobre as contribuições de Heidegger para pensar a gênese do lugar e destaca que:

O elemento poético é, para Heidegger, o que há de mais essencial no habitar do mundo, pois é ele que possibilita o habitar na quadratura, isto é, sobre a terra e sob o céu, ou seja, na proximidade do sagrado. Pensar o construir a partir do habitar na quadratura significa, para Heidegger, pensar antes de tudo a coisa construída, que configura, em si mesma e antes de tudo, um lugar (SARAMAGO, 2012, p. 218).

Ao refletirem sobre o conceito e a importância do lugar na compreensão geográfica do mundo, alguns autores enfatizam a grande influência que o tempo exerce sobre o lugar. Oliveira (2012, p. 3) inaugura a reflexão sobre "Qual o espaço do lugar?", afirmando que "o sentido do lugar implica o sentido da vida e, por sua vez, o sentido do tempo." Em outra passagem, a autora complementa que "lugar é um mundo de significados organizados, a um tempo estático e a outro dinâmico; são caminhos que se tornam lugares significativos" (OLIVEIRA, 2012, p. 12).

Na perspectiva ainda da relação tempo e lugar, Chaveiro (2012) acrescenta a noção de corpo e/ou da corporeidade ao debate, o qual assume nova perspectiva.

3. "Facticidade segundo Heidegger é o que caracteriza a existência como lançada no mundo, ou seja, à mercê dos fatos, ou no nível dos fatos e entregue ao determinismo dos fatos. Nesse sentido, a facticidade é um modo de ser do próprio homem e diferente da factualidade que é o modo de ser das coisas" (ABBAGNANO, 2003, p. 492). 
O lugar é um feixe ininterrupto de relações e, portanto, de práticas espaciais de diferentes sujeitos que, em sua luta diária pela existência, com valores e símbolos, com sensações e sentimentos, com intencionalidades e motivações, com a sua produção de sentido, transformam o corpo num ator de sua plataformas. Convém sintetizar: os lugares são arenas vitais para - e pela - ação das corporeidades, por onde o mundo torna factível, encarnado, real e possível (CHAVEIRO, 2012, p. 251).

Lugar é antes de tudo espaço, mas é também tempo e o é por diversas razões, como aponta Marandola Jr. (2012, p. 229). Este autor contribui para o debate, destacando a importância da relação entre lugar e espaço ao longo do tempo e das assunções do significado.

O tempo é vivido como memória, e por isso memória e identidade adensam lugar. A memória é a experiência vivida que o significa, definindo-o enquanto tal. Não é à toa que pensar em lugar é mais fácil recuando no tempo: lugar de nascimento, lugar de lembranças, lugar de saudade, lugar de memória, lugar de identidade (MARANDOLA JR., 2012, p. 229).

O tempo vivido como memória é uma característica nas composições de Chico Buarque e é uma das expressões de espaço e lugar. Pode-se afirmar, então, que memória é lugar e espaço. O lugar associado à memória pode ser identificado na letra da canção 'Maninha' e nas expressões de espaço que a narrativa apresenta. Vejamos a letra da canção para então refletir sobre a essência do lugar e do espaço.

\section{Maninha}

Chico Buarque, 1977

Se lembra da fogueira

Se lembra dos balões

Se lembra dos luares dos sertões

A roupa no varal, feriado nacional

$\mathrm{E}$ as estrelas salpicadas nas canções

Se lembra quando toda modinha

Falava de amor

Pois nunca mais cantei, oh maninha

Depois que ele chegou

Se lembra da jaqueira

A fruta no capim

Dos sonhos que você contou pra mim

Os passos no porão, lembra da assombração

E das almas com perfume de jasmim

Se lembra do jardim, oh maninha

Coberto de flor

Pois hoje só dá erva daninha

No chão que ele pisou

Se lembra do futuro 
Que a gente combinou

Eu era tão criança e ainda sou

Querendo acreditar que o dia vai raiar

Só porque uma cantiga anunciou

Mas não me deixe assim, tão sozinha

A me torturar

Que um dia ele vai embora, maninha

Prá nunca mais voltar...

Composta em 1977 por Chico Buarque a canção 'Maninha' foi utilizada como tema da novela Espelho Mágico, transmitida pela TV Globo, no mesmo ano da sua composição. O compositor, em entrevista a Wagner Homem, afirma que 'Maninha' é uma "canção zangada disfarçada de delicadeza, falando de uma infância imaginária" (HOMEM, 2009, p. 161).

A letra da canção dialoga com as observações de Chaveiro (2012), apresentando o tempo marcado pela lembrança: "se lembra da fogueira, se lembra dos balões". Quem se lembra, lembra-se de algo para representar a lembrança, os verbos da canção são apresentados no tempo passado. A lembrança e a memória são espaço antes de tempo, são 'onde' antes de 'quando'. A lembrança carrega o lugar e expressa o tempo. As definições do espaço ou as características do lugar da memória de 'Maninha' podem ser associadas à casa, ao jardim, ao quintal, a um espaço de afetividade. Como lembra Tuan (2004), a casa onde se viveu na infância é o primeiro lugar do qual se tem memória, ou ainda, “os pais são para as crianças o seu primeiro lugar”.

No caso da letra da canção acima, o que é lembrado são símbolos (estrelas, amor e jardim), são sensações (os passos no porão, lembranças da assombração), e são sentimentos (as músicas cantadas, o perfume das flores, os sonhos). As lembranças denunciam o lugar da memória que, nesta música, é identificado inicialmente como sertão: "se lembra dos luares do sertão".

A letra da canção é marcada pela passagem do tempo e pela simulação do diálogo entre o $\underline{\mathrm{Eu}}$ que se dirige a um $\underline{\mathrm{Tu}}$, representado pelo pronome você, -_"Os sonhos que você contou pra mim" - embora só haja a 'voz' da pessoa que resgata a memória, ou que resgata o lugar da memória, a essência do lugar se faz presente.

A letra da canção evoca, em dois momentos distintos, referenciais da música brasileira. O primeiro momento ocorre na passagem "se lembra dos luares dos sertões" que faz referência à música 'Luar do Sertão', de autoria de Luiz Gonzaga, uma importante referência para Chico Buarque. O segundo momento está na passagem "e as estrelas salpicadas nas canções”, que faz referência à música 'Chão de Estrelas', de Silvio Caldas, também outro importante compositor brasileiro.

O lugar ganha existência telúrica na medida em que o tempo auxilia o resgate da memória. Bosi (2000), em reflexão sobre o encontro dos tempos na poesia, pondera que:

a instância poética parece tirar do passado e da memória o direito à existência; não de um passado cronológico puro - o dos tempos já mortos -, mas de um 
passado presente cujas dimensões míticas se atualizam no modo de ser da infância e do inconsciente. A épica e a lírica são expressões de um tempo forte (social e individual) que já se adensou o bastante para ser evocado pela memória da linguagem (BOSI, 2000, p. 132).

O sertão na letra da canção reverbera lugar e assume feições próximas da conceituação de Melo (2011):

Sertão é o lugar nominado como sertão, o que se vê, se percebe, se compreende como sertão. Lugar que se propaga, se difunde, se diz sertão. Trata-se, portanto, de um espaço fundamentalmente subjetivo e movente, migrante, mutante, grafável e rasurável e, por isso, de difícil apreensão (MELO, 2011, p. 66).

O sertão é lugar e é também espaço, sobretudo quando assume as características descritivas do local. O sertão pode ser o quintal de uma casa quando tomado por lugar cheio de significados, sensações, cheiros, cores e sentidos, ou pode ser uma porção da Terra. A escala do lugar é tão relativa quanto a escala do sertão. Lugar e sertão são líquidos - fluem, correm, assumem a forma dos 'recipientes' em que se encontram. Nesta poesia, o sertão de Chico pode, sem dúvida, ser o quintal da casa, lugar recheado de memória, e de um tempo pretérito que guarda lembranças afetivas.

O lugar, no entanto, nem sempre é passado, mas também é tempo no futuro; é o que está por vir, é o desconhecido e, por ser ausente, causa sensações, ansiedades e sentimentos do mundo desconhecido. Esse lugar do futuro, construído a partir das temporalidades que ainda estão por vir, também aparece em composições de Chico Buarque, como acontece na letra da canção 'Nina'.

\section{Nina}

Chico Buarque, 2011

Nina diz que tem a pele cor de neve

E dois olhos negros como o breu

Nina diz que, embora nova

Por amores já chorou que nem viúva

Mas acabou, esqueceu

Nina adora viajar, mas não se atreve

Num país distante como o meu

Nina diz que fez meu mapa

E no céu o meu destino rapta

$\mathrm{O}$ seu

Nina diz que se quiser eu posso ver na tela

A cidade, o bairro, a chaminé da casa dela

Posso imaginar por dentro a casa

A roupa que ela usa, as mechas, a tiara

Posso até adivinhar a cara que ela faz

Quando me escreve

Nina anseia por me conhecer em breve 
Me levar para a noite de Moscou

Sempre que esta valsa toca

Fecho os olhos, bebo alguma vodca

E vou...

Chico Buarque inicia 'Nina', apresentando-a com 'a pele cor de neve', menção essa feita ao poema 'Cantiga para não morrer', de Ferreira Gullar (1999), que começa com os versos: "Quando você se for embora, moça branca como a neve, me leve".

O poeta (eu lírico) apresenta 'Nina' e algumas de suas características, todavia ele ainda não a conhece. Passeia pela letra da canção, acompanhado do devaneio: Nina anseia por me conhecer em breve'. O capricho da imaginação exercido na letra da canção coloca o lugar num tempo futuro, algo que ainda vai chegar e que ainda não se materializou: 'a casa dela em Moscou', ou 'a noite de Moscou' ainda não são conhecidas, mas estão nos planos futuros do poeta. O tempo marca a narrativa e o lugar está presente. O lugar nesta composição assume diferentes feições. A relação do casal adota o espaço virtual como lugar e ocorre no ciberespaço, uma dimensão virtual da realidade constituída por ações informacionais, como ocorre na passagem 'Nina diz que se quiser eu posso ver na tela. A cidade, o bairro, a chaminé da casa dela'. No ato de 'ver pela tela' estão implícitas as tecnologias hoje disponíveis para conversar virtual ou remotamente, ligando o tempo e comprimindo o espaço. O lugar é também constituído por sensações e sentidos, como no verso 'posso imaginar por dentro da casa'. Ao mesmo tempo que o lugar é uma lembrança de um lugar ausente, sem claras definições, também é real, porque apresenta as sensações e os sentidos. A letra da canção revela as geografias, costurando as referências espaciais e temporais com as sensações evocadas pela memória sensorial e percebidas pelos sentidos da visão, do tato, e da audição. Nina tem cheiro, sabor, formato, cor e textura. Essas sensações evocadas pela memória sensorial na letra da canção se realizam não só pelas referências espaciais urbanas, onde se desenrola a trama, mas também pelas relações do casal no tempo e no mundo.

Para Cosgrove (2000), a imaginação é considerada aquilo que dá significado ao mundo e pode ser considerada uma categoria central nos estudos da Geografia cultural, uma vez que possibilita analisar as relações socioespaciais dos indivíduos com os lugares e com o coletivo.

A letra da canção fala de devaneios, de amores por correspondência, de amores virtuais e de lembranças que podem acontecer no futuro. O lugar está sendo construído pela relação virtual e pelas lembranças do devaneio. O futuro está presente como dimensão do lugar e, não por acaso, a canção acaba com "eu vou".

O lugar é presente, é passado e é, também, futuro. Possui características relacionais ao sujeito que o constrói, seja pela lembrança passada, pelo devaneio ou pelo capricho da imaginação, que pode ocupar tempos diferentes e caracterizar lugares distintos. Sobre o passado e o futuro na imaginação cultural, Cosgrove (2000) observa que

a linearidade do tempo humano implica que o passado e o futuro são coordenadas necessárias à fixação do presente. Tanto o passado como o futuro são espaços da 
imaginação; nenhum deles existe como um dado proveniente dos sentidos. Ao atribuir significado ao mundo do presente, a imaginação constrói narrativas que juntam o passado e o futuro numa forma de síntese (COSGROVE, 2000, p. 48).

\section{Considerações finais}

Partindo da premissa que sujeito e mundo coexistem, o lugar onde o sujeito estabelece relações possui uma gama de significados e valores que são inseparáveis da experiência de quem os vivencia. O lugar tem um sentido e é parte essencial de nossa existência.

As letras das canções de Chico Buarque alcançam a realidade pela linguagem poética e revelam referências espaciais e temporais a partir do sentido dado pela percepção e afeição. Apresentam-se como possibilidades de leitura do conjunto de experiências que orientam o comportamento do sujeito no mundo e que acabam no limite, por desenvolver um projeto existencial a partir do corpo. As letras das canções de Chico Buarque são manifestações da arte de compor com palavras textos poéticos, porque são formas de expressão e de sentido. A música é uma linguagem utilizada há milhares de anos por homens e mulheres se comunicarem e é uma expressão carregada de referências espaciais, temporais e sentimentais na medida em que marca lugares e relações sociais a partir da troca do sujeito com o mundo.

A obra de Chico Buarque composta de mais de trezentas canções é o seu mundo e o diálogo geográfico que estabelecemos com uma pequena parte dessa obra são aproximações com o seu mundo. Não é possível apreender na totalidade o conjunto da obra, mas apenas nos aproximarmos dela, percebê-la e presenciá-la.

A percepção para Merleau-Ponty (2009) é caracterizada como o nosso primeiro contato com as coisas, com o mundo. Assim, ela é anterior aos juízos, valores e objetivações. Portanto, perceber não é definir. Perceber dilata os sentidos e nos apresenta um horizonte. Contudo, devido à relação ambígua entre perceber e percebido, esse acesso ao mundo será sempre inacabado. As aproximações são permanentes e não cessam e as experiências geradas pelas aproximações são construídas a partir das referências espaciais, temporais e sentimentais. Portanto, as grafias espaciais, temporais e afetivas que se revelam nas letras das canções são aproximações geográficas com o mundo. A construção plural, coletiva e permanente do pensamento geográfico em aproximações com o humanismo é adensada pelas percepções que, somadas às referências espaciais e temporais revelam e constroem uma experiência de mundo para o sujeito.

\section{Referências}

ABBAGnANO, N. Dicionário de filosofia. Trad. Alfredo Bosi. 4 ed. São Paulo: Martins Fontes, 2003.

BESSE, J. M. Geografia e existência: a partir da obra de Eric Dardel. In: DARDEL, Eric. O homem e a terra: natureza da realidade geográfica. Trad. Werther Holzer. São Paulo: Perspectiva, 2011. (p. 111-139) 
BOSI, A. O ser e o tempo da poesia. 7 ed. São Paulo: Companhia das Letras, 2000.

CERTEAU, M. de; GIARD, L.; MAYOL, P. A invenção do cotidiano: 2 morar, cozinhar. 5 ed. Trad. Ephraim F. Alves e Lúcia E. Orth. Petrópolis: Vozes, 2003.

CERTEAU, M. de. A Invenção do cotidiano: artes de fazer. Trad. Ephraim Ferreira Alves. 18 ed. Petrópolis: Vozes, 2012.

CHAVEIRO, E. F. Corporeidade e Lugar: elos da produção da existência. In MARANDOLA JR. E.; HOLZER, W.; OLIVEIRA, L. (orgs.) Qual o espaço do lugar? Geografia, epistemologia, fenomenologia. São Paulo: Perspectiva, 2012. (p. 249-279).

CORRÊA, R. L. Espaço, um conceito-chave da Geografia. In: CASTRO, I. et al (Org.). Geografia: conceitos e temas. Rio de Janeiro : Bertrand Brasil, 1995, p. 15-47.

COSGROVE, D. Mundos de significados: Geografia Cultural e imaginação. In: CORRÊA, R. L.; ROSENDAHL, Z. (orgs.) Geografia cultural: um século (2). Trad. Tania Shepherd. Rio de Janeiro: EDUERJ, 2000. (p. 33-60)

GULLAR, F. Toda poesia. 9 ed. Rio de Janeiro: José Olympio, 1999.

HEIDEGGER, M. Ensaios e conferências. Trad. Emmanuel Carneiro Leão, Gilvan Fogel e Márcia Sá Cavalcante Schuback. 5 ed. Petrópolis: Vozes, 2008.

. Ser e Tempo. Parte I. Trad. Márcia Sá Cavalcante Schuback. 15 ed. Petrópolis: Vozes, 2005. Vozes, 2003.

. A caminho da linguagem. Trad. Márcia Sá Cavalcante Schuback. Petrópolis:

HOLZER, W. Mundo e lugar: ensaio de geografia fenomenológica. In MARANDOLA JR. E.; HOLZER, W.; OLIVEIRA, L. (orgs.) Qual o espaço do lugar? Geografia, epistemologia, fenomenologia. São Paulo: Perspectiva, 2012. (p. 281-304).

. Uma dimensão fenomenológica sobre os conceitos de paisagem e lugar, território e meio ambiente. Território, Rio de Janeiro, ano II, no 3, p. 77-85, jul./dez. 1997.

HOMEM, W. Histórias de canções: Chico Buarque. São Paulo: Leya, 2009.

MARANDOLA JR, E. Lugar enquanto circunstancialidade. In MARANDOLA JR. E.; HOLZER, W.; OLIVEIRA, L. (orgs.) Qual o espaço do lugar? Geografia, epistemologia, fenomenologia. São Paulo: Perspectiva, 2012. (p. 227-248).

MELLO, J. B. F. DE. Geografia Humanística: a perspectiva da experiência vivida e uma crítica radical ao Positivismo. Revista Brasileira de Geografia. Rio de Janeiro, n. 52, p. 91-115, 1990.

MELO, A. F. de. Sertões do mundo: uma epistemologia. 2011. Vol. 1. 117 f. Tese (Doutorado em Geografia) - Instituto de Geociências - UFMG - Belo Horizonte, 2011.

OLIVEIRA, L. de. O sentido do lugar. . In MARANDOLA JR. E.; HOLZER, W.; OLIVEIRA, L. (orgs.) Qual o espaço do lugar? Geografia, epistemologia, fenomenologia. São Paulo: Perspectiva, 2012. (p. 3-16). 
PÁDUA, L. T. S. A topologia do Ser: lugar, espaço e linguagem no pensamento de Martin Heidegger. 2005. 301 f. Tese (Doutorado em Filosofia) - PUC, Rio de Janeiro, 2005.

RELPH, E. C. As bases fenomenológicas da Geografia. Geografia, Rio Claro, SP, vol. 4, numero 7, 1979, pp. 01-25.

. Rational landscapes and humanistic geography. London: Rowman \& Littlefield, 1981.

SANTOS, M. A natureza do espaço: técnica e tempo, razão e emoção. 4 ed. São Paulo: EdUSP, 2009.

SARAMAGO, L. Como ponta de lança: o pensamento do lugar em Heidegger. In MARANDOLA JR. E.; HOLZER, W.; OLIVEIRA, L. (orgs.) Qual o espaço do lugar? Geografia, epistemologia, fenomenologia. São Paulo: Perspectiva, 2012. (p. 193-225).

TUAN. Y. F. Topofilia: um estudo da percepção, atitudes e valores do meio ambiente. Trad. Lívia de Oliveira. São Paulo: DIFEL, 1980.

. Espaço e lugar: a perspectiva da experiência. Trad. Lívia de Oliveira. São Paulo: DIFEL, 1983.

2004.

. Place, art and self. Santa Fe, New Mexico: Center for American Places Inc.,

Carolina Machado Rocha Busch Pereira

Doutora em Geografia Humana pela Universidade de São Paulo - USP, mestre em Geografia pela Universidade Estadual Paulista - UNESP Presidente Prudente e graduada em Geografia pela Universidade Estadual de Londrina - UEL. Atualmente é Professora Adjunta do curso de Geografia (licenciatura/ bacharelado) e do Programa de Pós-Graduação em Geografia da Universidade Federal do Tocantins - Campus de Porto Nacional.

Via Local 51 quadra 13 lote 36 - Jardim dos Ipês - Porto Nacional, TO - CEP. 77500-000

E-mail: carolinamachado@uft.edu.br

Recebido para publicação em maio de 2015 Aprovado para publicação em agosto de 2015 